\title{
Enxerto de mucosa do palato duro: complicações na área doadora - Relato de casos
}

\author{
Hard palate mucosa grafting:donor site complications - Case reports
}

\author{
José Byron Vicente Dias Fernandes ${ }^{1}$ \\ Tânia Pereira Nunes ${ }^{2}$ \\ Suzana Matayoshi ${ }^{3}$ \\ Eurípedes da Mota Moura ${ }^{4}$
}

Universidade de São Paulo, Faculdade de Medicina, Departamento de Oftalmologia, Hospital das Clínicas, Setor de Plástica Ocular.

Médico Pós-graduando, nível Doutorado, do departamento de Oftalmologia da Faculdade de Medicina da Universidade de São Paulo - USP.

Médica Colaboradora do setor de Plástica Ocular da Faculdade de Medicina da Universidade de São Paulo - USP.

Médica Doutora Assistente do setor de Plástica Ocular da Faculdade de Medicina da Universidade de São Paulo - USP.

${ }^{4}$ Médico Doutor Assistente Chefe do setor de Plástica Ocular da Faculdade de Medicina da Universidade de São Paulo - USP.

Endereço para correspondência: Tânia Pereira Nunes. Rua Cristiano Viana, 116 - apto 32 - São Paulo (SP) CEP 05411-000.

Recebido para análise em 31.07.2001

Versão revisada recebida em 28.03.2003

Aprovação em 19.09.2003

Nota Editorial: Pela análise deste trabalho e por sua anuência na divulgação desta nota, agradecemos à Dra. Lucia Miriam Dumont Lucci.

\begin{tabular}{|l|}
\hline RESUMO \\
\hline O enxerto de mucosa do palato duro é substituto satisfatório na \\
reconstrução da lamela posterior da pálpebra (tarso e conjuntiva). Sua \\
superfície mucosa, a resistência à contração e sua fácil retirada são \\
vantagens sobre outros enxertos. Apresentamos duas complicações \\
na região do sítio doador e discutimos as prováveis fisiopatologias \\
destas complicações.
\end{tabular}

Descritores: Enxerto de palato duro; Defeito de lamela posterior da pálpebra

\section{INTRODUĈ̃̃}

A pálpebra pode ser dividida anatomicamente em 2 porções: lamela anterior, constituída por pele e músculo orbicular e lamela posterior, formada pelo tarso e conjuntiva. Vários tipos de enxertos e retalhos são utilizados na reconstrução da lamela posterior da pálpebra: enxerto ou retalho tarsoconjuntival, enxerto de cartilagem auricular, mucosa bucal, retalho periostal, esclera preservada, mucosa nasal e mucosa do palato duro ${ }^{(1-5)}$.

$O$ enxerto de mucosa do palato duro foi descrito pela primeira vez na reconstrução de pálpebra por Siegel, que o utilizou após remoção tumoral ${ }^{(1)}$. Posteriormente, este tipo de enxerto foi descrito na correção de retração palpebral inferior principalmente na decorrente de oftalmopatia tireoidiana, entrópio cicatricial, tratamento de triquíase, paralisia facial com lagoftalmo e reconstrução de cavidade anoftálmica ${ }^{(2-7)}$.

Algumas vantagens na utilização deste material são: tratar-se de um tecido autógeno, de obtenção relativamente fácil, apresentar uma superfície mucosa composta de epitélio esquamoso estratificado com queratinização variável e que posteriormente se torna não-queratinizado, além de apresentar um suporte estrutural com retração mínima ${ }^{(1-3,5-6,8)}$.

As desvantagens deste tipo de enxerto são: a falta de familiaridade do oftalmologista com a região doadora ${ }^{(2-3)}$, o enxerto pode conter glândula salivar menor levando à secreção mucóide de difícil tratamento ${ }^{(8)}$, a metaplasia do epitélio ocorre de 3 a 6 meses após a cirurgia ${ }^{(3)}$, tornando a técnica desaconselhável para reconstruções da pálpebra superior devido à abrasão da córnea ${ }^{(4)}$. Queixas de dor e desconforto no pós-operatório são comuns ${ }^{(3,6)}$.

Os objetivos deste trabalho são apresentar dois casos de complicações cirúrgicas após retirada de mucosa de palato duro, analisar suas possíveis causas e enfatizar os cuidados no momento da retirada do enxerto para diminuir a chance de complicações. 


\section{RELATO DOS CASOS}

\section{Caso 1}

Paciente de 48 anos, sexo masculino, branco, apresentava exoftalmo endócrino e retração palpebral bilateral. Já havia sido submetido à tireoidectomia subtotal e cirurgia para correção de estrabismo vertical. Foi programada descompressão orbitária, com incisão sub-ciliar e enxerto de palato duro, para correção de retração palpebral inferior à direita.

A mucosa do palato duro foi colhida após anestesia e hemostasia local da região doadora, utilizando xilocaína $2 \%$ com epinefrina 1:100.000 (2) . O enxerto de palato duro varia de 7 a $10 \mathrm{~mm}$ de largura por 25 a $30 \mathrm{~mm}$ de comprimento. Anteriormente é limitado pelas pregas palatinas e posteriormente 2 a $3 \mathrm{~mm}$ antes da junção do palato duro com palato mole, devido a presença da artéria palatina ${ }^{(5,7)}$. A linha palatina central deve ser evitada ${ }^{(2,9)}$.

Quanto mais próximo o enxerto de palato duro for da linha mediana, maior a probabilidade de se obter uma glândula salivar menor ${ }^{(9)}$. Cuidado deve ser tomado para não se retirar o enxerto na espessura total, evitando-se atingir o mucoperiósteo ${ }^{(1,5-6)}$. A hemostasia local foi realizada per-operatório com cautério bipolar conforme necessidade. Após a descompressão da órbita direita, foi realizada a colocação do enxerto de mucosa de palato duro na pálpebra inferior no plano conjuntival, sem intercorrências, sendo prescrito colírio antibiótico e antiinflamatório no pós-operatório.

No $4^{\circ}$ pós-operatório o paciente desenvolveu hemorragia em palato duro. Foi hospitalizado e submetido à cauterização do ponto sangrante, localizado na região anterior, próximo às pregas palatinas. Evoluiu bem sem nenhuma outra intercorrência.

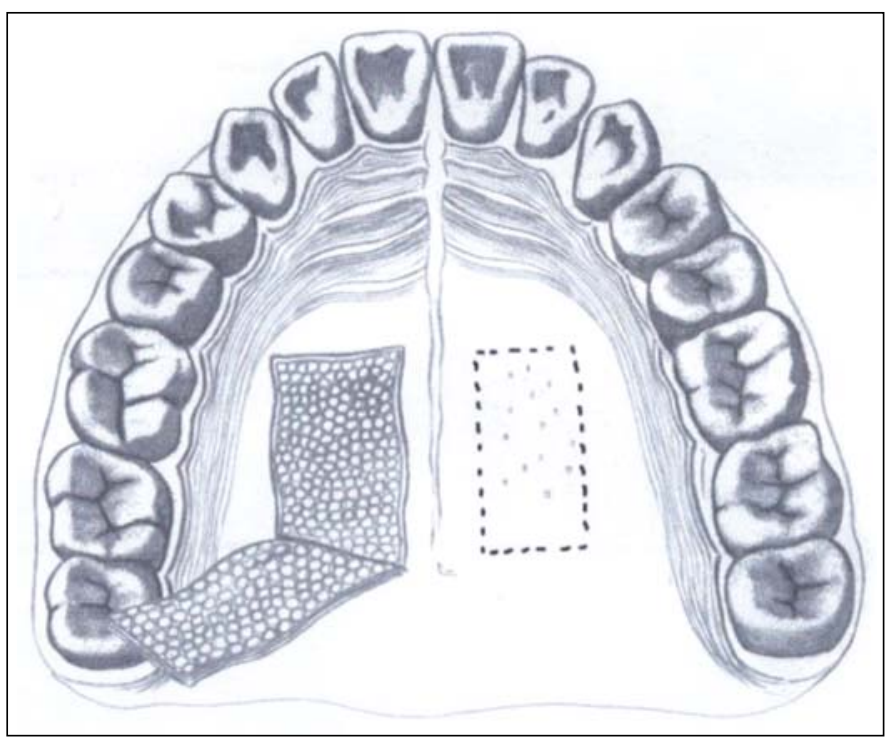

Figura 1 - Área doadora de mucosa de palato duro

\section{Caso 2}

Paciente de 50 anos, sexo feminino, branca, foi submetida à remoção de lesão tumoral em pálpebra inferior à esquerda, sendo programada sua reconstrução através da técnica de Mustardé(10). A lamela posterior foi reconstruída com enxerto de palato duro. A mucosa do palato duro foi colhida com a técnica descrita no caso 1 . O ato cirúrgico não apresentou complicações. Foram prescritos colírio e pomada com associação de antibiótico e antiinflamatório na região ocular e antiséptico bucal para higiene da área doadora.

No $7^{\circ}$ pós-operatório, a paciente queixou-se de sensação de presença de líquido na cavidade nasal durante a deglutição; no exame da cavidade oral, observou-se a presença de fístula oro-nasal na porção posterior do palato duro. O tratamento foi feito com o uso de placa protetora para palato e antiséptico oral. Após 3 semanas houve oclusão do orifício com fechamento da mucosa da cavidade bucal.

\section{DISCUSSÃO}

O enxerto de mucosa de palato duro é um substituto da lamela posterior na reconstrução palpebral ${ }^{(4)}$. Pode ser colhido sob anestesia local ou geral ${ }^{(2,9)}$. A área doadora é demarcada anteriormente pelas pregas palatinas, posteriormente $3 \mathrm{~mm}$ anterior ao palato mole, lateralmente pela gengiva e medialmente pela linha mediana do palato duro (Figura 1).

A espessura total do enxerto é de aproximadamente $2 \mathrm{~mm}$, deve-se evitar o aprofundamento da incisão para não lesar o periósteo e os vasos sangüíneos maiores. Considera-se que a integridade do periósteo seja um fator importante na cicatrização da ferida ${ }^{(2,7)}$.

Complicações associadas com o enxerto de palato duro podem desenvolver-se na área doadora e na receptora. Já foram descritas complicações como: necrose do enxerto, espessura palpebral aumentada, alterações corneanas causadas pelo enxerto, queratinização persistente do enxerto, secreção mucosa no sítio receptor produzida por glândulas salivares presentes no enxerto, desconforto oral prolongado, fístula oro-nasal e quadro de infecção local ${ }^{(5-9,11)}$.

A complicação mais temida da área doadora é a hemorragia no intra e/ou no pós-operatório ${ }^{(6)}$. O nosso primeiro caso apresentou esta complicação no $4^{\circ}$ dia de pós-operatório, necessitando hospitalização e cauterização do sítio doador. Alguns autores descrevem esta intercorrência como de fácil resolução com manobras simples, como a compressão local com o polegar durante alguns minutos ${ }^{(6,12)}$; porém o paciente descrito em nosso estudo apresentou quadro de sangramento constante, com alteração dos níveis de hematócrito e hemoglobina, necessitando intervenção cirúrgica. Esta complicação está relacionada com a profundidade da lesão cirúrgica e comprometimento de vasos maiores, e neste caso o tratamento de escolha foi a cauterização.

Em relação às fístulas oro-nasais, Kim e colaboradores descreveram pela primeira vez o seu aparecimento após retirada de 


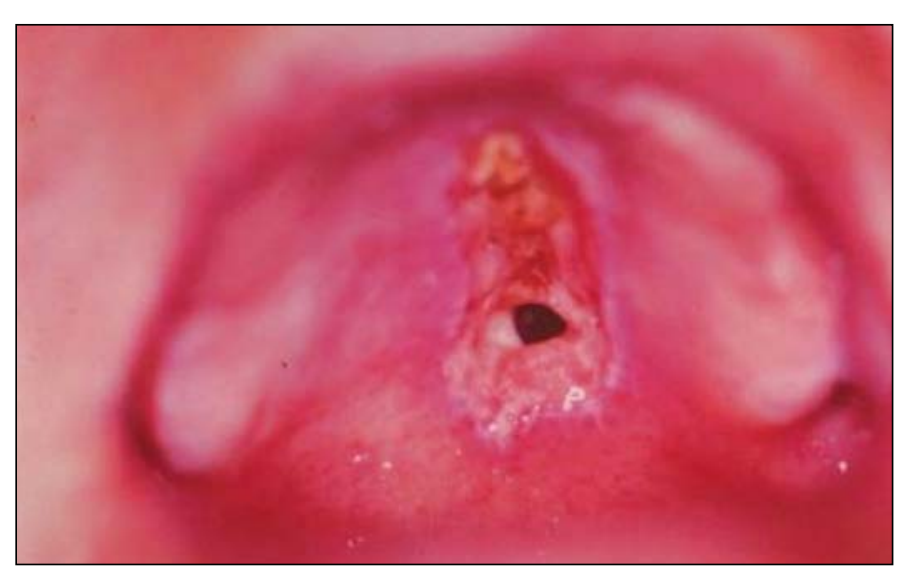

Figura 2 - Fístula oro-nasal: $4^{\circ}$ pós-operatório

mucosa de palato duro ${ }^{(11)}$. O paciente do caso 2 apresentou fistula oro-nasal na primeira semana do pós-operatório, o orifício localizava-se entre palato duro e palato mole (Figura 2).

\section{CONCLUSÃO}

Mecanismos iatrogênicos, como isquemia local, pressão dos instrumentos cirúrgicos na área doadora e uso excessivo de cauterização, podem contribuir para a necrose óssea e conseqüente formação de fistula ${ }^{(11)}$. A extensão da fístula para o palato mole observada no caso 2 pode ser explicada pela cauterização excessiva dos tecidos, que levou à necrose e perfuração no pós-operatório. Este tipo de complicação acarreta risco de infecção para cavidade nasal e sinusal, principalmente por anaeróbios. O tratamento da paciente foi realizado com o uso de uma placa protetora de palato e anti-séptico local com fechamento total da fístula (Figura 3).

O uso de mucosa de palato duro tem sido bastante preconizado na reconstrução palpebral. A técnica para sua remoção é relativamente fácil, porém o sítio doador é pouco familiar ao oftalmologista, o que é um fator importante para o desenvolvimento de complicações no intra e no pós-operatório, sendo necessário um melhor conhecimento anatômico da região bucal e saber como conduzir eventuais complicações.

\section{ABSTRACT}

The graft of hard palate mucosa is a satisfactory substitute for posterior eyelid lamella (tarsus and conjunctiva) in eyelid reconstruction. The advantages of hard palate over other graft materials are: its mucosal surface, minimal contraction during

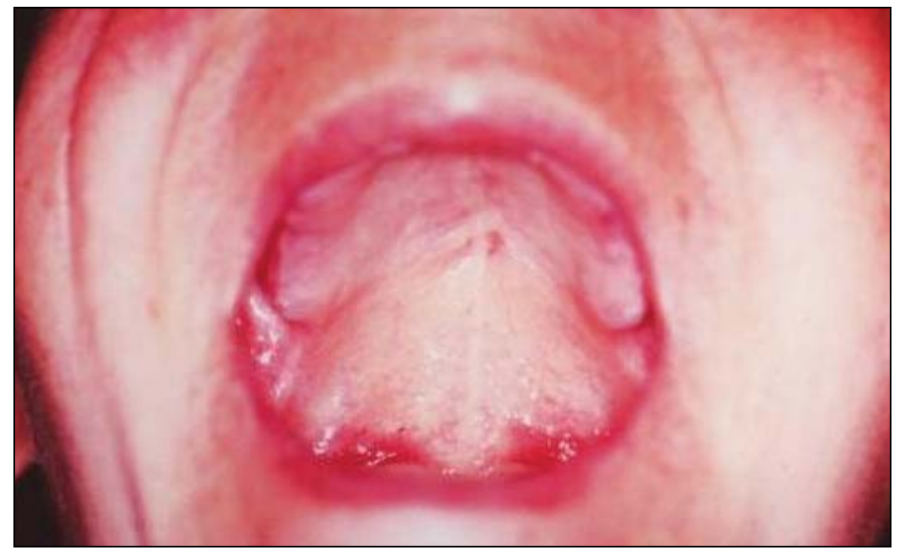

Figura 3 - Fístula oro-nasal cicatrizada

healing, and easiness of harvesting. We present two palatal donor site complications and we discuss the probable pathophysiology of these complications.

Keywords: Hard palate graft; Posterior eyelid lamella defect.

\section{REFERÊNCIAS}

1. Siegel RJ. Palatal grafts for eyelid reconstruction. Plast Reconstr Surg 1985; 76:411-4.

2. Bartley GB, Kay PP. Posterior lamellar eyelid reconstruction with a hard palate mucosal graft. Am J Ophthalmol 1989;107:609-12.

3. Cohen MS, Shorr N. Eyelid reconstruction with hard palate mucosa grafts [commented on Ophthal Plast Reconstr 1994:10:64-5]. Ophthal Plast Reconstr 1992;8:183-95.

4. Goldberg RA, Joshi AR, McCann JD, Shorr N. Management of severe cicatricial entropion using shared mucosal grafts. Arch Ophthalmol 1999;117:1255-9.

5. Patel BC, Patipa McAnderson RL, Mcheish W. Management of postblepharoplasty lower eyelid retraction with hard palate grafts and lateral tarsal strip. Plast Reconstr Surg 1997;99:1251-60.

6. Holck DE, Foster JA, Dutton JJ, Dillon HD. Hard palate mucosal grafts in the treatment of the contracted socket. Ophthal Plast Reconstr Surg 1999;15:202-9.

7. Kersten RC, Kulwin DR, Levartovsky S, Tiradellis H, Tse D. Management of lower-lid retraction with hard palate mucosa grafting. Arch Ophthalmol 1990;108:1339-43.

8. Pelletier CR, Jordan DR, Brownstein S, Li S. An Unusual complication associated with hard palate mucosal grafts: presumed minor salivary gland secretion. Ophthal Plast Reconstr Surg 1998;14:256-60.

9. Beatty RL, Harris G, Bauman GR, Mills MP. Intraoral palatal mucosal graft harvest. Ophthal Plast Reconstr Surg 1993;9:120-4.

10. Mustardé JC. Repair and reconstruction in the orbital region. New York; Churchill Livingstone; 1991.

11. Kim JW, Kikkawa DO, Lemke BN. Donor site complications of hard palate mucosal grafting. Ophthal Plast Reconstr Surg 1997;13:36-9.

12. Shorr N. Madame Butterfly procedure: total lower eyelid reconstruction in three layers utilizing a hard palate graft: management of the unhappy postblepharoplasty patient with round eye and scleral show. Int J Aest Restor Surg 1995;3:3-26. 